\title{
Nine-year analysis of isolated pathogens and antibiotic susceptibilities of microbial keratitis from a large referral eye center in southern China
}

This article was published in the following Dove Press journal:

Infection and Drug Resistance

\section{Lixia Lin* \\ Fang Duan* \\ Yao Yang \\ Bingsheng Lou \\ Lingyi Liang \\ Xiaofeng Lin}

Zhongshan Ophthalmic Center, State Key Laboratory of Ophthalmology, Sun Yatsen University, Guangzhou, People's Republic of China

*These authors contributed equally to this work
Correspondence: Xiaofeng Lin; Lingyi

Liang

State Key Laboratory of Ophthalmology, Zhongshan Ophthalmic Center, Sun Yatsen University, Guangzhou 510060,

People's Republic of China

Tel +86I 8922103830

Email linxiaof@mail.sysu.edu.cn;

lingyiliang@mail.qq.com
Purpose: To analyze the genus profile of isolated pathogens and antibiotic susceptibility trends of microbial keratitis over nine years at a large referral eye center in southern China. Methods: Data of corneal specimens from January 2010 to August 2018 of patients clinically diagnosed with infectious keratitis were obtained from the center's microbiology database. Results with positive cultures along with antibiotic susceptibility were reviewed and analyzed.

Results: We collected and reviewed 7,229 specimens, including 3,092 with positive cultures. Among them, 1,630 (52.72\%) were bacterial, 1781 (57.60\%) were fungal, and 319 $(10.32 \%)$ were coinfected. A significant decreasing trend was observed in the isolates of Gram-positive cocci $(\mathrm{r}=-0.711, P=0.032)$, among which the proportion of coagulasenegative staphylococcus (CNS) was also reduced ( $\mathrm{r}=-0.883, P=0.002)$. In contrast, an increasing trend in the proportion of Gram-negative bacilli was observed $(r=0.661$, $P=0.053)$. The susceptibility rates of Gram-positive cocci to cephalosporins were near $90 \%$, which was relatively high compared to fluoroquinolones. Fluoroquinolones represented the antibiotics to which Gram-negative bacilli were the most susceptible. Their susceptibility to moxifloxacin was $78.79 \%$. The overall performance of aminoglycosides and vancomycin was both around $70 \%$. The susceptibility of Gram-positive cocci to several antibiotics including levofloxacin $(\mathrm{r}=-0.717, P=0.03)$, tobramycin $(\mathrm{r}=-0.933, P<0.001)$, cefazolin $(\mathrm{r}=$ -0.964, $P<0.001$ ), ceftazidime ( $\mathrm{r}=-0.929, P=0.003)$, chloramphenicol $(\mathrm{r}=-0.929, P=0.003)$, and cefuroxime $(\mathrm{r}=-0.829, P=0.042)$ decreased over time. The susceptibility of Gramnegative bacilli to ofloxacin increased over time $(\mathrm{r}=0.854, P=0.004)$, whereas that to cefazolin $(\mathrm{r}=-0.833, P=0.005)$ and chloramphenicol $(\mathrm{r}=-0.886, P=0.019)$ decreased over time.

Conclusion: From 2010 to 2018 in Zhongshan Ophthalmic Center, most isolates from infectious keratitis were Gram-positive cocci (mainly CNS), which decreased over time, with an increase in Gram-positive bacilli. More than half of the antibiotics showed reducing trend of susceptibilities, and the antibiotic resistance situation in southern China was not encouraging.

Keywords: infectious keratitis, bacterial keratitis, antibiotic resistance, time trend

\section{Introduction}

Microbial keratitis is an ophthalmic emergency, which can cause irreversible sight loss if not treated promptly. ${ }^{1}$ Owing to the delay associated with the results of specimen culturing, which remains the mainstay of pathogenic diagnosis of infectious keratitis, the treatment of microbial keratitis usually starts with empiric antibiotic treatment, 
based on clinical features of the corneal lesions and previous knowledge of the antibacterial spectrum of antibiotics. ${ }^{2}$

However, the distribution of pathogens not only varies by region but also evolves rapidly over time, depending on various risk factors. ${ }^{3-6}$ More importantly, microorganisms can gradually develop resistance following exposure to antibiotics, thereby lowering the success rate of empiric antimicrobial treatment. ${ }^{7}$

Therefore, it is necessary to update the pathogenic and antibiotic susceptibility trends associated with microbial keratitis, to provide a regional reference for initial treatment before a thorough microbiological examination. In light of this, we collected the laboratory results of infectious keratitis from January 2010 to August 2018 at the largest referral eye institute in southern China, to analyze the time trends of pathogen proportions and antibiotic susceptibilities.

\section{Materials and methods}

Chronological results of microbiological examinations of patients who had been clinically diagnosed with infectious keratitis were collected from January 2010 to August 2018. The data were obtained anonymously from the microbiology database, with the omission of personal information, and the operation of sample collection and clinical care. The study was approved by the Ethics Committee of Zhongshan Ophthalmic Center. All protocols and interpretation of the results were conducted according to the Clinical and Laboratory Standards Institute guidelines. ${ }^{8}$

All specimens were obtained from corneal lesions via scraping with a platinum spatula. Smear staining of the specimens was optional and was performed according to the orders of the clinicians. The specimens were then inoculated into bacterial or fungal media. ${ }^{9-11}$ In addition to blood agar, chocolate agar, brain heart infusion broth, thioglycolate (broth), Sabouraud agar, sheep blood agar, and potato glucose agar, anaerobic blood agar has been included among the list of media since 2017. All bacterial colonies were subjected to species identification using the VITEK 2 compact automated system (BioMérieux, Marcy l'Etoile, France). Antibiotics, including cephalosporins (cefazolin, ceftazidime, and cefuroxime sodium); fluoroquinolones (ofloxacin, levofloxacin, and moxifloxacin); aminoglycosides (tobramycin and neomycin); chloramphenicol; and vancomycin, were used for the susceptibility tests. Not every antibiotic was tested for identical quantity of specimens, because some antibiotics were suspended for one or several months, owing to various practical reasons. Vancomycin and moxifloxacin were not tested until 2017. The genera of fungi were identified by experienced microbiological technicians, according to colony characteristics, as well as microscopic characteristics of the hyphae and spores.

\section{Statistical analysis}

All analyses were performed with commercially available software (SPSS 16.0; SPSS Inc., Chicago, IL, USA). All results of culture-positive specimens were analyzed. The incubation results and susceptibility data are presented as categorical variables, expressed as percentages. Thus, differences between groups were compared using the chisquared test. To determine the time trends of bacterial proportions and antibiotic susceptibility, the Spearman's rank correlation coefficient was used. ${ }^{12-14}$ Gram-negative cocci and Gram-positive bacilli were omitted from the analysis, as the annual sample sizes were too small. A twotailed Student's $t$-test was used to determine statistical significance, which was set at $P<0.05$.

\section{Results}

A total of 7,229 specimens were collected and reviewed. Positive cultures with species identification were achieved in $3,092(42.77 \%)$ specimens. Of the 3,092 positive cultures, 1,630 $(52.72 \%)$ were positive for bacterial species, $1,781(57.60 \%)$ were positive for fungal species, and 319 $(10.32 \%)$ were co-infected with both bacteria and fungi. Otherwise, no Acanthamoeba species were isolated from specimen cultures; however, amoeba cysts were detected by smear staining in five specimens.

The genus distribution of bacteria and fungi identified in the present study are presented in Tables 1 and 2, respectively. The most common bacteria isolated were Grampositive cocci $(\mathrm{n}=1139,69.88 \%)$, the majority of which were coagulase-negative staphylococci (CNS) ( $=885$, $54.29 \%$ ), the most common of which was Staphylococcus epidermidis $(\mathrm{n}=493,30.25 \%)$. The second most frequently detected bacteria was Pseudomonas aeruginosa $(\mathrm{n}=182$, $11.17 \%)$.

The most frequently detected fungal organism was Fusarium species ( $\mathrm{n}=728,40.88 \%$ ), followed by Aspergillus species ( $\mathrm{n}=376,21.11 \%)$ and Mucor $(\mathrm{n}=185,10.39 \%)$. Among 319 dual-positive specimens, the most common bacterial component was Staphylococcus epidermidis $(\mathrm{n}=137$, $42.95 \%$ ), and the most frequent fungus detected was Fusarium species (n=118, 36.99\%) (Table 3). 
Table I Genus distribution of bacteria isolated from 2010 to 2018 in Zhongshan Ophthalmic Center

\begin{tabular}{|l|l|}
\hline Genus & Specimens, $\mathbf{n}$ (\%) \\
\hline Gram-positive cocci & $1139(69.88)$ \\
Coagulase-negative staphylococci (CNS) & $885(54.29)$ \\
$\quad$ Staphylococcus epidermidis & $493(30.25)$ \\
Other CNS & $392(24.05)$ \\
Streptococci & $80(4.91)$ \\
Staphylococcus aureus & $49(3.01)$ \\
Kocuria spp. & $35(2.15)$ \\
Micrococci & $24(1.47)$ \\
Enterococci & $19(1.17)$ \\
Tetracocci & $13(0.80)$ \\
Klebsiella spp. & $11(0.67)$ \\
Other Gram-positive cocci & $23(1.41)$ \\
\hline Gram-negative bacilli & $399(24.48)$ \\
Pseudomonas aeruginosa & $182(11.17)$ \\
Acinetobacter spp. & $43(2.64)$ \\
Other Pseudomonas spp. & $52(3.19)$ \\
Serratia spp. & $17(1.04)$ \\
Escherichia coli & $13(0.80)$ \\
Burkholderia spp. & $14(0.86)$ \\
Enteric bacilli & $10(0.61)$ \\
Other Gram-negative bacilli & $68(4.17)$ \\
\hline Gram-positive bacilli & $82(5.03)$ \\
Bacilli subtilis & $16(0.98)$ \\
Corynebacterium & $15(0.92)$ \\
Propionibacterium acnes & $7(0.43)$ \\
Other Gram-positive bacilli & $44(2.70)$ \\
\hline Gram-negative cocci & $10(0.61)$ \\
Total & $1630(100.00)$ \\
\hline
\end{tabular}

Table 2 Genus distribution of fungi isolated from 2010 to 2018 in Zhongshan Ophthalmic Center

\begin{tabular}{|l|l|}
\hline Genus & Specimens, n (\%) \\
\hline Filamentous fungi & $1690(94.89)$ \\
Fusarium sp. & $728(40.88)$ \\
Aspergillus sp. & $376(21.11)$ \\
Mucor & $185(10.39)$ \\
Helminthosporium & $149(8.37)$ \\
Curvularia & $85(4.77)$ \\
Penicillium sp. & $79(4.44)$ \\
Alternaria sp. & $20(1.12)$ \\
Other filamentous fungi & $68(3.82)$ \\
\hline Non-filamentous fungi & $91(25.11)$ \\
Candida sp. & $70(3.93)$ \\
Zymoid epiphyte & $19(1.07)$ \\
Yeast & $2(0.11)$ \\
\hline Total & $1781(100.00)$ \\
\hline
\end{tabular}

As shown in Figure 1, there was a significant trend of decline in the number of isolates of Gram-positive cocci $(\mathrm{r}=$ $-0.711, P=0.032$ ) recovered during the study period. Moreover, the proportion of CNS among the Gram-positive cocci also presented a similar trend of decline $(\mathrm{r}=-0.883$, $P=0.002$ ). In contrast, we observed an increasing trend in the percentage of recovered Gram-negative bacilli ( $\mathrm{r}=0.661$, $P=0.053$ ).

Detailed susceptibility rates of isolated bacteria are presented in Table 4. The susceptibility of Gram-positive cocci to cephalosporins was close to $90 \%$, which was relatively high in comparison to fluoroquinolones. Gram-negative bacilli showed the greatest susceptibility to fluoroquinolones, with a rate of $78.79 \%$ to moxifloxacin. However, Gramnegative bacilli showed low sensitivity to cephalosporins, especially cefazolin. The overall sensitivity to aminoglycosides was around $70 \%$. In addition, sensitivity to vancomycin was also around $70 \%$, which showed no considerable differences from the overall sensitivity to other antibiotics.

As presented in Figure 2, most antibiotics manifested a roughly similar trend of decline in bacterial susceptibility, with the exception of ofloxacin. Some data were absent for neomycin, chloramphenicol and cefuroxime, as susceptibility tests were suspended for some periods. The Spearman's rank correlation coefficients $(r)$ representing time trends in antibiotic susceptibility are summarized in Table 5.

Susceptibility of Gram-positive cocci to several antibiotics declined from 2010 to 2018 , including levofloxacin ( $\mathrm{r}=-0.717, P=0.03)$, tobramycin $(\mathrm{r}=-0.933, P<0.001)$, cefazolin ( $\mathrm{r}=-0.964, P<0.001)$, ceftazidime ( $\mathrm{r}=-0.929$, $P=0.003$ ), chloramphenicol ( $\mathrm{r}=-0.929, P=0.003)$, and cefuroxime $(\mathrm{r}=-0.829, P=0.042)$. The susceptibility rates of Gram-negative bacilli to levofloxacin and tobramycin showed no significant changes. Susceptibility to ofloxacin increased from 2010 to 2018 ( $\mathrm{r}=0.854, P=0.004$ ). Susceptibility rates to cefazolin $(\mathrm{r}=-0.833, P=0.005)$ and chloramphenicol ( $\mathrm{r}=-0.886, P=0.019)$ both showed a decline over the same period.

\section{Discussion}

Even though new technologies, such as polymerase chain reaction, in-vivo confocal microscopy, and next-generation sequencing, have been applied in some studies and have even been used in some clinical institutions, the pathogenic diagnosis of infectious keratitis by specimen culturing remains the mainstay, owing to the various practical limitations of new technologies. ${ }^{15-17}$ As culture is a time-consuming job, the time trends of pathogens and antibiotic sensitivity remain important 
Table 3 Frequency of dual-cultured organisms from 2010 to 2018 in Zhongshan Ophthalmic Center

\begin{tabular}{|l|l|l|l|l|l|}
\hline Specimens, n (\%) & Fusarium sp. & Aspergillus sp. & Other filamentous fungi & Non-filamentous fungi & Total \\
\hline Staphylococcus epidermidis & $41(12.85)$ & $39(12.23)$ & $49(15.36)$ & $8(2.5 I)$ & $137(42.95)$ \\
Other CNS & $29(29.09)$ & $10(3.13)$ & $23(7.21)$ & $0(0.00)$ & $62(19.44)$ \\
Other bacteria & $29(29.09)$ & $12(3.76)$ & $46(14.42)$ & $0(0.00)$ & $87(27.27)$ \\
Pseudomonas aeruginosa & $19(5.96)$ & $7(2.19)$ & $7(2.19)$ & $0(0.00)$ & $33(10.34)$ \\
Total & $118(36.99)$ & $68(21.32)$ & $125(39.18)$ & $8(2.5 I)$ & $319(100.00)$ \\
\hline
\end{tabular}

Abbreviation: CNS, coagulase negative staphylococcus.

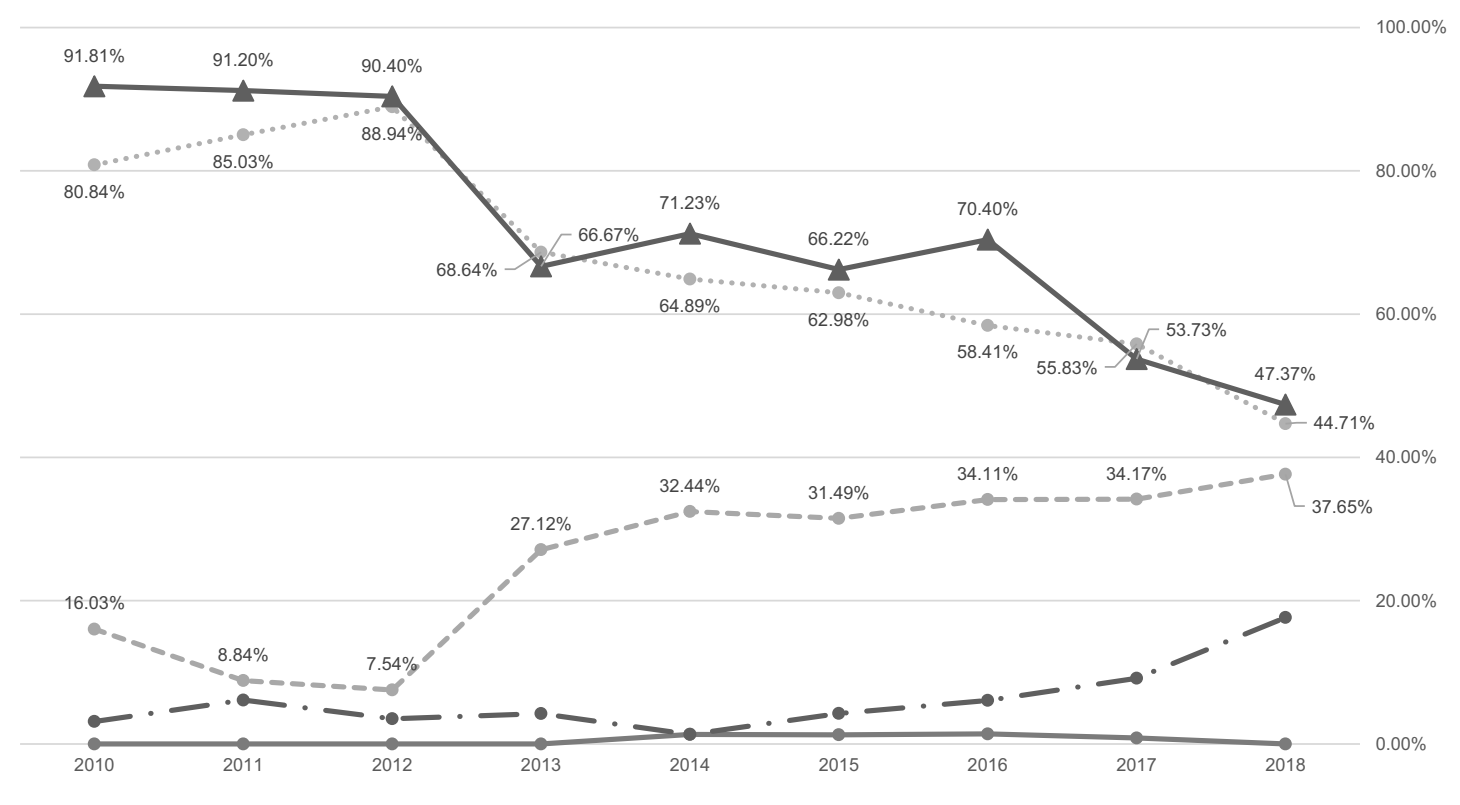

$-\rightarrow$ Gram-negative bacilli $\longrightarrow$ Gram-negative cocci $\quad \longrightarrow$ Gram-positive bacilli $\quad \cdots \cdots$ Gram-positive cocci $\longrightarrow$ CNS proportion

Figure I Time trends of bacteria isolated from 2010 to 2018 in Zhongshan Ophthalmic Center. There was a significant decreasing trend in the isolates of Gram-positive cocci $(r=-0.71 \mathrm{I}, P=0.032)$ from 2010 to 2018. Meanwhile, the proportion of coagulase-negative staphylococcus (CNS) among the Gram-positive cocci also presented a similar decreasing trend $(r=-0.883, P=0.002)$. On the other hand, a statistically suggestive increasing trend in the percentage of recovered Gram-negative bacilli was observed $(r=0.66 \mathrm{I}, P=0.053)$.

for effective guidance in the initial treatment of infectious keratitis in practice.

\section{Organism distribution and time trends of microbial proportions}

In the present study, fungi accounted for slightly more than half of the isolated organisms, which is consistent with the findings of our previous study $(58.14 \%)$. ${ }^{9}$ Although the main etiologies of microbial keratitis are diverse worldwide, reports of fungal proportions are fairly consistent among various studies in northern China and other developing regions in Asia (46.21 81.95\%). ${ }^{18-21}$ The populations of contact lens wearers are much higher in developed regions. As a result, contact lens-related bacterial keratitis is more commonly detected in these regions than in other developing countries. $^{21-23}$

Gram-positive cocci comprise the predominant bacteria detected in most studies of bacterial keratitis, including the present study. ${ }^{18,21,24-26}$ The majority of Gram-positive cocci are CNS, which are opportunistic pathogens that commonly colonize the healthy ocular surface and usually cause impairment under conditions of trauma or hypoimmunitiy. A recent study of the ocular surface microbiome provided relevant evidence via sequencing of the samples harvested from the inferior bulbar conjunctiva and reported that Staphylococcus epidermidis was recovered from $73 \%$ of the healthy subjects. ${ }^{27}$ In the present study, CNS was more commonly detected in coinfected specimens, manifesting the opportunistic character of CNS. Therefore, positive culture results 
Table 4 Overall susceptibility rate of isolated bacteria to different antibiotics in Zhongshan Ophthalmic Center

\begin{tabular}{|c|c|c|c|c|c|}
\hline $\begin{array}{l}\text { Susceptibility } \\
\text { rate }\end{array}$ & $\begin{array}{l}\text { Gram-positive } \\
\text { cocci }\end{array}$ & $\begin{array}{l}\text { Gram-negative } \\
\text { bacilli }\end{array}$ & $\begin{array}{l}\text { Gram-negative } \\
\text { cocci }\end{array}$ & $\begin{array}{l}\text { Gram-positive } \\
\text { bacilli }\end{array}$ & $\begin{array}{l}\text { Total } \\
\text { specimens }\end{array}$ \\
\hline Levoflaxacin & $\begin{array}{l}62.79 \% \\
(697 / 1110)\end{array}$ & $\begin{array}{l}75.27 \% \\
(283 / 376)\end{array}$ & $\begin{array}{l}50 \% \\
(4 / 8)\end{array}$ & $\begin{array}{l}71.43 \% \\
(55 / 77)\end{array}$ & $\begin{array}{l}66.14 \% \\
(1039 / 157 I)\end{array}$ \\
\hline Tobramycin & $\begin{array}{l}64.92 \% \\
(692 / 1066)\end{array}$ & $\begin{array}{l}71.09 \% \\
(268 / 377)\end{array}$ & $\begin{array}{l}66.67 \% \\
(6 / 9)\end{array}$ & $\begin{array}{l}51.22 \% \\
(42 / 82)\end{array}$ & $\begin{array}{l}65.71 \% \\
(1008 / 1534)\end{array}$ \\
\hline Neomycin & $\begin{array}{l}77.89 \% \\
(775 / 995)\end{array}$ & $\begin{array}{l}71.00 \% \\
(191 / 269)\end{array}$ & $\begin{array}{l}62.50 \% \\
(5 / 8)\end{array}$ & $\begin{array}{l}80.33 \% \\
(49 / 61)\end{array}$ & $\begin{array}{l}76.52 \% \\
(1020 / 1333)\end{array}$ \\
\hline Cefazolin & $\begin{array}{l}89.60 \% \\
(74 I / 827)\end{array}$ & $\begin{array}{l}21.25 \% \\
(75 / 353)\end{array}$ & $\begin{array}{l}75.00 \% \\
(3 / 4)\end{array}$ & $\begin{array}{l}47.62 \% \\
(20 / 42)\end{array}$ & $\begin{array}{l}68.43 \% \\
(839 / 1226)\end{array}$ \\
\hline Ceftazidime & $\begin{array}{l}85.13 \% \\
(704 / 827)\end{array}$ & $\begin{array}{l}50.71 \% \\
(179 / 353)\end{array}$ & $\begin{array}{l}50 \% \\
(2 / 4)\end{array}$ & $\begin{array}{l}45.24 \% \\
(19 / 42)\end{array}$ & $\begin{array}{l}73.74 \% \\
(904 / 1226)\end{array}$ \\
\hline Ofloxacin & $\begin{array}{l}70.11 \% \\
(624 / 890)\end{array}$ & $\begin{array}{l}58.22 \% \\
(124 / 2 \mid 3)\end{array}$ & $\begin{array}{l}42.86 \% \\
(3 / 7)\end{array}$ & $\begin{array}{l}75.36 \% \\
(52 / 69)\end{array}$ & $\begin{array}{l}68.11 \% \\
(803 / 1179)\end{array}$ \\
\hline Chloramphenicol & $\begin{array}{l}69.57 \% \\
(599 / 861)\end{array}$ & $\begin{array}{l}72.09 \% \\
(129 / 179)\end{array}$ & $\begin{array}{l}75 \% \\
(3 / 4)\end{array}$ & $\begin{array}{l}81.58 \% \\
(31 / 38)\end{array}$ & $\begin{array}{l}70.43 \% \\
(762 / 1082)\end{array}$ \\
\hline Cefuroxime & $\begin{array}{l}90.94 \% \\
(572 / 629)\end{array}$ & $\begin{array}{l}67.94 \% \\
(89 / 131)\end{array}$ & $\begin{array}{l}75 \% \\
(3 / 4)\end{array}$ & $\begin{array}{l}84.09 \% \\
(37 / 44)\end{array}$ & $\begin{array}{l}86.76 \% \\
(701 / 808)\end{array}$ \\
\hline Moxifloxacin & $\begin{array}{l}60.22 \% \\
(112 / 186)\end{array}$ & $\begin{array}{l}78.79 \% \\
(26 / 33)\end{array}$ & I & $\begin{array}{l}66.67 \% \\
(4 / 6)\end{array}$ & $\begin{array}{l}63.11 \% \\
(142 / 225)\end{array}$ \\
\hline Vancomycin & $\begin{array}{l}72.49 \% \\
(137 / 189)\end{array}$ & $\begin{array}{l}64.71 \% \\
(22 / 34)\end{array}$ & I & $\begin{array}{l}83.33 \% \\
(5 / 6)\end{array}$ & $\begin{array}{l}71.62 \% \\
(164 / 229)\end{array}$ \\
\hline
\end{tabular}

Notes: The numerator in the parenthesis represents the number of specimens sensitive to the listed antibiotic, and the denominator represents the number of specimens that underwent susceptibility test with the listed antibiotics.

with CNS do not necessarily determine the etiology of infectious keratitis, and a preponderance of Gram-positive cocci should be interpreted with caution.

In the present study, we discovered a declining shift in CNS isolation, which might lead to a similar trend in Grampositive cocci. Sun and co-authors reported a nearly opposite shifting trend in bacterial proportions in northern China from 2006 to 2015 . $^{13}$ Diversity in the trends of bacterial shifts among different regions are not uncommon. Many studies have demonstrated that topical antibiotic usage might alter the populations of conjunctival microflora, especially those of opportunistic pathogens, which can also be influenced by long-term usage of contact lenses or environmental pollution. ${ }^{28-30}$ Nevertheless, the increasing trend in the proportion of Gram-negative bacilli recovered in the present study is notable, as these species usually cause more severe consequences, owing to their comparatively higher levels of antibiotic resistance and strong virulence. ${ }^{31}$

\section{Profiles and time trends of bacterial susceptibilities to antibiotics}

Antibiotic resistance is a worldwide challenge. Overall susceptibility rates show compromise at some level, both in overall bacterial and in species-specific tests. Gram-positive cocci showed the highest susceptibility rates to cephalosporins (close to 90\%). These results are higher than those of a report from northern China, in which susceptibility rates to ceftazidime were less than $50 \%$ from 2006 to $2015 .^{13}$ However, the susceptibility rate of Gram-positive cocci to vancomycin in the present study were considerably low compared to other reports from northern China and other regions (around 90 100\%). ${ }^{2,12,13}$ Vancomycin is considered the last antibiotic effective for Gram-positive bacterial infections. Even though no data has been presented regarding methicillin-resistant Gram-positive cocci in the present study, as we did not routinely test for methicillin or oxacillin, there is no need to emphasize the burden of antibiotic resistance burden revealed by prominent vancomycin resistance.

Gram-negative bacteria were most susceptible to fluoroquinolones and aminoglycosides in the present study. However, ofloxacin, which has been classified as a first-line antibiotic for the treatment of bacterial keratitis in the $\mathrm{UK}^{22}$ was merely half as effective. Furthermore, most of the susceptibility rates determined in the present study were lower than those of other reports worldwide. ${ }^{3,12,22,32,33}$ These low susceptibility rates might be associated with the increasing trend of Gram-negative bacilli infections, as antibiotic-resistant keratitis is more difficult to treat. 

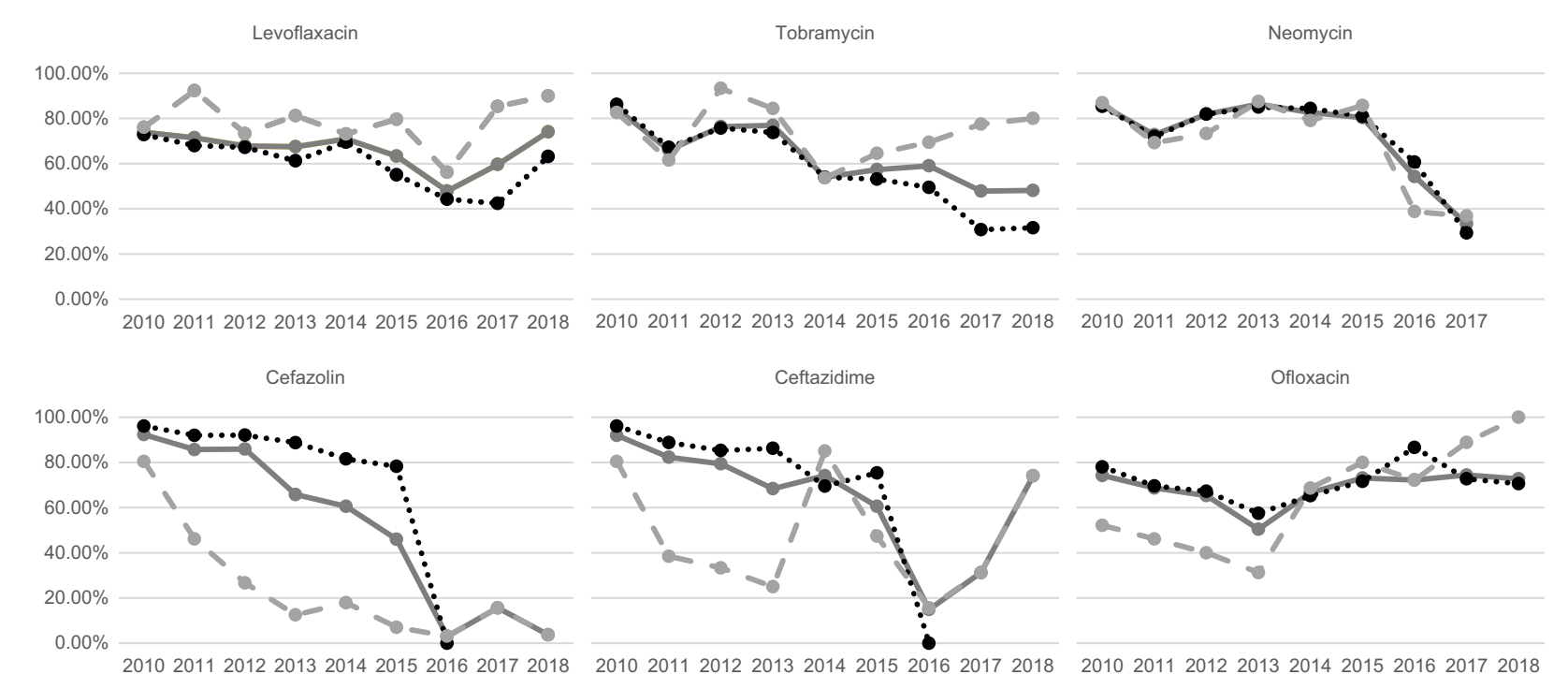

201020112012201320142015201620172018

20102011201220132014201520162017
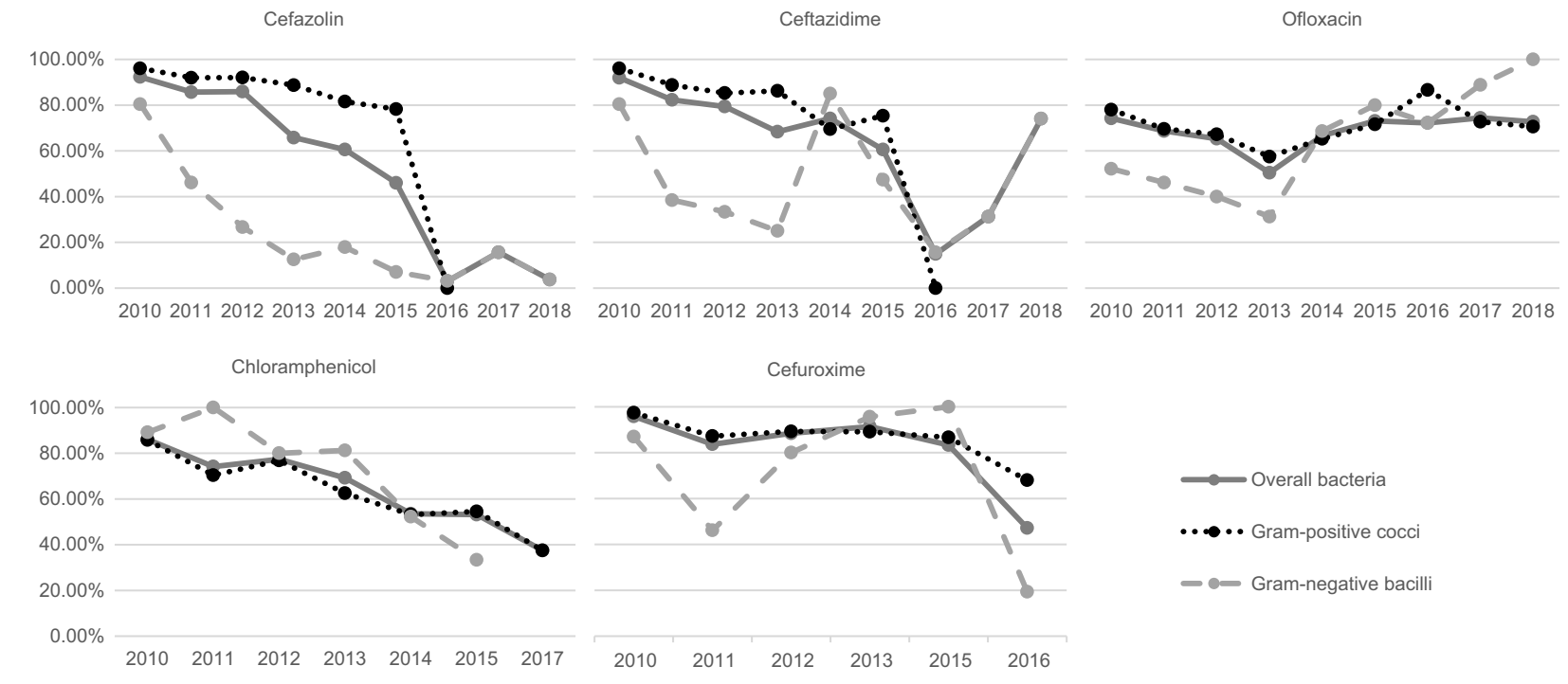

Figure 2 Time trends of bacterial susceptibilities from 2010 to 2018 in Zhongshan Ophthalmic Center. Most of the antibiotics manifested decreasing trends of susceptibility, except ofloxacin. Some data were absent for neomycin, chloramphenicol, and cefuroxime, as susceptibility tests were suspended for some periods. Time trend analysis of Gram-negative cocci and Gram-positive bacilli were omitted due to small sample sizes.

Table 5 Spearman rank correlation coefficients of antibiotic susceptibility by year

\begin{tabular}{|l|l|l|l|}
\hline r Value & $\begin{array}{l}\text { Overall } \\
\text { bacteria }\end{array}$ & $\begin{array}{l}\text { Gram- } \\
\text { positive } \\
\text { cocci }\end{array}$ & $\begin{array}{l}\text { Gram- } \\
\text { negative } \\
\text { bacilli }\end{array}$ \\
\hline Levoflaxacin & -0.333 & $-0.717 *$ & -0.083 \\
Tobramycin & $-0.850 * *$ & $-0.933 *$ & -0.167 \\
Neomycin & -0.619 & -0.690 & -0.524 \\
Cefazolin & $-0.933 * *$ & $-0.964 * *$ & $-0.833 * *$ \\
Ceftazidime & $-0.783 *$ & $-0.929 * *$ & -0.200 \\
Ofloxacin & 0.317 & 0.233 & $0.817 * *$ \\
Chloramphenicol & $-0.946 * *$ & $-0.929 * *$ & $-0.886 *$ \\
Cefuroxime & -0.771 & $-0.829 *$ & -0.029 \\
\hline
\end{tabular}

Notes: Time trend analyses of Gram-negative cocci and Gram-positive bacilli were not performed due to small sample sizes. $* P<0.05$, $* * P<0.0$ I.

More than half of the antibiotics evaluated in the present study yielded a trend of reducing susceptibility, which was not comparable with the results of other reports on keratitis. In northern China, the susceptibility of bacterial keratitis showed no decline from 2006 to 2015. ${ }^{13}$ Lalitha et $\mathrm{al}^{33}$ and Tan et $\mathrm{al}^{22}$ have also reported that antibiotic resistance rates were generally stable over a decade in southern India and the UK, respectively. However, antibiotic resistance is not an independent issue restricted to the discipline of ophthalmology. Antibiotic susceptibilities reported in different studies from the same region might corroborate each other. A recent study from Guangzhou showed an increasing trend of multidrug-resistant bacteria in neonatal invasive infections. ${ }^{34}$ Another study conducted in Guangzhou also reported the high and continuously increasing resistance rates among Gram-positive bacteria. ${ }^{35}$ Furthermore, the need for antibiotic usage in agricultural and animal farming is growing along with economic growth in China. Zhang et $\mathrm{al}^{36}$ reported that 92,700 tons of antibiotics were consumed in China in 2013 alone, with approximately even distribution between animals and humans. Considerable usage of antibiotics in China has become a huge burden to the ecological environment. Studies have demonstrated that antibiotic resistance is substantially increased in various aspects of the environment, such as water, soil, plants, and 
animals. $^{37-40}$ Furthermore, antibiotic resistance genes might flow and accumulate along the food chain. ${ }^{41,42}$ The urgent need for antibiotic control has long drawn the attention of health management officials. However, with the establishment of a nationwide surveillance system aimed at gathering information regarding antibiotic resistance, ${ }^{43}$ and policies aimed at reducing the abuse of antibiotics, the control of antibiotic resistance remains a long, arduous, uphill struggle.

Our study had potential limitations. First, as a referral hospital-based study, the results might have been affected by sampling bias. Second, the lack of Acanthamoeba-specific media is a limitation that cannot be ignored, as Acanthamoeba keratitis is an important type of refractory keratitis. Moreover, we did not present the clinical characteristics of the pathogens or analyze the relationship between the pathogens and clinical outcomes. Nonetheless, we have added one more piece to the puzzle of the current situation regarding antibiotic susceptibility, by providing a general overview of microbial keratitis at a large referral eye center in southern China.

\section{Conclusions}

During the period from 2010 to 2018, the proportion of Gram-positive cocci (mainly CNS) isolated from cases of keratitis comprised the majority, yet showed a trend of decline, whereas Gram-negative bacilli are suspected to be increasing in number at the largest eye center in southern China. More than half of the antibiotics under investigation yielded a reducing trend of susceptibility. Thus, antibiotic resistance in southern China remains a considerable challenge, and the urgent implementation of more policies regarding its control is warranted.

\section{Acknowledgments}

This study was supported by grants from Fundamental Research Funds of the State Key Laboratory of Ophthalmology (30306020240020130, 3030902113030), and a grant from the Natural Science Foundation of Guangdong Province (2018A030313585).

\section{Disclosure}

The authors report no conflicts of interest in this work.

\section{References}

1. Limberg MB. A review of bacterial keratitis and bacterial conjunctivitis. Am J Ophthalmol. 1991;112(4 Suppl):2S-9S.
2. Lin A, Rhee MK, Akpek EK, et al. Bacterial keratitis preferred practice pattern(R). Ophthalmology. 2019;126(1):P1-P55. doi:10.1016/j.ophtha.2018.10.018

3. Sun X, Deng S, Li R, et al. Distribution and shifting trends of bacterial keratitis in north China (1989-98). $\mathrm{Br} J$ Ophthalmol. 2004;88(2):165-166.

4. Hong J, Chen J, Sun X, et al. Paediatric bacterial keratitis cases in Shanghai: microbiological profile, antibiotic susceptibility and visual outcomes. Eye (Lond). 2012;26(12):1571-1578. doi:10.1038/ eye.2012.210

5. Walkden A, Fullwood C, Tan SZ, et al. Association between season, temperature and causative organism in microbial keratitis in the UK. Cornea. 2018;37(12):1555-1560. doi:10.1097/ ICO.0000000000001748

6. Srinivasan M, Gonzales CA, George C, et al. Epidemiology and aetiological diagnosis of corneal ulceration in Madurai, south India. Br J Ophthalmol. 1997;81(11):965-971.

7. Kim SJ, Toma HS. Ophthalmic antibiotics and antimicrobial resistance a randomized, controlled study of patients undergoing intravitreal injections. Ophthalmology. 2011;118(7):1358-1363. doi:10.1016/j.ophtha.2010.12.014

8. NCCLS CaLSIF. Performance standards for antimicrobial susceptibility testing: 16th Informational supplement;.Vol. 25.

9. Lin L, Lan W, Lou B, et al. Genus distribution of bacteria and fungi associated with keratitis in a large eye center located in Southern China. Ophthalmic Epidemiol. 2017;24(2):90-96. doi:10.1080/ 09286586.2016 .1254250

10. Long C, Liu B, Xu C, Jing Y, Yuan Z, Lin X. Causative organisms of post-traumatic endophthalmitis: a 20 -year retrospective study. $B M C$ Ophthalmol. 2014;14:34. doi:10.1186/1471-2415-14-34

11. Duan F, Yang Y, Yuan Z, Zheng Y, Cheng Z, Lin X. Clinical features and visual acuity outcomes in culture-positive endogenous fungal endophthalmitis in Southern China. $J$ Ophthalmol. 2017;2017:3483497. doi:10.1155/2017/3483497

12. Hernandez-Camarena JC, Graue-Hernandez EO, Ortiz-Casas M, et al. Trends in microbiological and antibiotic sensitivity patterns in infectious keratitis: 10-year experience in Mexico City. Cornea. 2015;34(7):778-785. doi:10.1097/ICO.0000000000000428

13. Zhang Y, Wang ZQ, Sun XG. [Etiological analysis and in vitro drug sensitivity of bacterial keratitis in northern China in the period of 2006-2015]. Zhonghua Yan Ke Za Zhi. 2017;53(9):662-667. doi:10.3760/cma.j.issn.0412-4081.2017.09.006

14. Lichtinger A, Yeung SN, Kim P, et al. Shifting trends in bacterial keratitis in Toronto: an 11-year review. Ophthalmology. 2012;119 (9):1785-1790. doi:10.1016/j.ophtha.2012.03.031

15. Chidambaram JD, Prajna NV, Palepu S, et al. In vivo confocal microscopy cellular features of host and organism in bacterial, fungal, and acanthamoeba keratitis. Am J Ophthalmol. 2018;190:24-33. doi:10.1016/j.ajo.2018.03.010

16. Inata K, Miyazaki D, Uotani R, et al. Effectiveness of real-time PCR for diagnosis and prognosis of varicella-zoster virus keratitis. Jpn J Ophthalmol. 2018;62(4):425-431. doi:10.1007/ s10384-018-0604-7

17. Inoue T, Ohashi Y. Utility of real-time PCR analysis for appropriate diagnosis for keratitis. Cornea. 2013;32(Suppl 1):S71-S76. doi:10.1097/ICO.0b013e3182a2c79f

18. Pan XJ, Jiang T, Zhu H, Liu PP, Zhou ZY, Mao AJ. Corneal infection in Shandong peninsula of China: a 10-year retrospective study on 578 cases. Int $J$ Ophthalmol. 2016;9(1):53-57. doi:10.18240/ ijo.2016.01.09

19. Xie L, Zhong W, Shi W, Sun S. Spectrum of fungal keratitis in north China. Ophthalmology. 2006;113(11):1943-1948. doi:10.1016/j. ophtha.2006.05.035

20. Bharathi MJ, Ramakrishnan R, Vasu S, Meenakshi PR. Aetiological diagnosis of microbial keratitis in South India - a study of 1618 cases. Indian J Med Microbiol. 2002;20(1):19-24. 
21. Khor WB, Prajna VN, Garg P, et al. The Asia cornea society infectious keratitis study: a prospective multicenter study of infectious Keratitis in Asia. Am J Ophthalmol. 2018;195:161-170. doi:10.1016/j.ajo.2018.07.040

22. Tan SZ, Walkden A, Au L, et al. Twelve-year analysis of microbial keratitis trends at a UK tertiary hospital. Eye (Lond). 2017;31 (8):1229-1236. doi:10.1038/eye.2017.55

23. Ung L, Bispo PJ, Shanbhag SS, Gilmore MS, Chodosh J. The persistent dilemma of microbial keratitis: global burden, diagnosis, and antimicrobial resistance. Surv Ophthalmol. 2018. doi:10.1016/j. survophthal.2018.12.003

24. Termote K, Joe AW, Butler AL, et al. Epidemiology of bacterial corneal ulcers at tertiary centres in Vancouver. B.C. Can J Ophthalmol. 2018;53(4):330-336. doi:10.1016/j.jcjo.2017.11.001

25. Jeng BH, Gritz DC, Kumar AB, et al. Epidemiology of ulcerative keratitis in Northern California. Arch Ophthalmol. 2010;128 (8):1022-1028. doi:10.1001/archophthalmol.2010.144

26. Ibrahim YW, Boase DL, Cree IA. Epidemiological characteristics, predisposing factors and microbiological profiles of infectious corneal ulcers: the Portsmouth corneal ulcer study. $\mathrm{Br} J$ Ophthalmol. 2009;93(10):1319-1324. doi:10.1136/bjo.2008.151167

27. Wen X, Miao L, Deng Y, et al. The influence of age and sex on ocular surface microbiota in healthy adults. Invest Ophthalmol Vis Sci. 2017;58(14):6030-6037. doi:10.1167/iovs.17-22957

28. Liesegang TJ. Contact lens-related microbial keratitis: part II: pathophysiology. Cornea. 1997;16(3):265-273.

29. Golofit-Szymczak M, Gorny RL, Lawniczek-Walczyk A, Cyprowski M, Stobnicka A. Bacterial and fungal aerosols in the work environment of cleaners. Med Pr. 2015;66(6):779-791. doi: $10.13075 / \mathrm{mp} .5893 .00349$

30. Montan PG, Setterquist H, Marcusson E, Rylander M, Ransjo U. Preoperative gentamicin eye drops and chlorhexidine solution in cataract surgery. Experimental and clinical results. Eur J Ophthalmol. 2000;10(4):286-292. doi:10.1177/112067210001000403

31. Adler A, Friedman ND, Marchaim D. Multidrug-resistant gram-negative bacilli: infection control implications. Infect Dis Clin North Am. 2016;30(4):967-997. doi:10.1016/j. idc. 2016.08 .001

32. Hsu HY, Ernst B, Schmidt EJ, Parihar R, Horwood C, Edelstein SL. Laboratory results, epidemiologic features, and outcome analyses of microbial keratitis: a 15-year review from St. Louis. Am J Ophthalmol. 2019;198:54-62. doi:10.1016/j.ajo.2018.09.032
33. Lalitha P, Manoharan G, Karpagam R, et al. Trends in antibiotic resistance in bacterial keratitis isolates from South India. $\mathrm{Br}$ $J$ Ophthalmol. 2017;101(2):108-113. doi:10.1136/bjophthalmol2016-308487

34. Gao K, Guan X, Zeng L, et al. An increasing trend of neonatal invasive multidrug-resistant group B streptococcus infections in southern China, 2011-2017. Infect Drug Resist. 2018;11:2561-2569. doi:10.2147/IDR.S178717

35. Xu Z, Xie J, Peters BM, et al. Longitudinal surveillance on antibiogram of important Gram-positive pathogens in Southern China, 2001 to 2015. Microb Pathog. 2017;103:80-86. doi:10.1016/j. micpath.2016.11.013

36. Zhang QQ, Ying GG, Pan CG, Liu YS, Zhao JL. Comprehensive evaluation of antibiotics emission and fate in the river basins of China: source analysis, multimedia modeling, and linkage to bacterial resistance. Environ Sci Technol. 2015;49(11):6772-6782. doi:10.1021/acs.est.5b00729

37. Verraes C, Van Boxstael S, Van Meervenne E, et al. Antimicrobial resistance in the food chain: a review. Int $J$ Environ Res Public Health. 2013;10(7):2643-2669. doi:10.3390/ijerph10072643

38. Greig J, Rajic A, Young I, Mascarenhas M, Waddell L, LeJeune J. A scoping review of the role of wildlife in the transmission of bacterial pathogens and antimicrobial resistance to the food Chain. Zoonoses Public Health. 2015;62(4):269-284. doi:10.1111/ zph. 12147

39. Zou S, Xu W, Zhang R, Tang J, Chen Y, Zhang G. Occurrence and distribution of antibiotics in coastal water of the Bohai Bay, China: impacts of river discharge and aquaculture activities. Environ Pollut. 2011;159(10):2913-2920. doi:10.1016/j.envpol.2011.04.037

40. Hu Y, Gao GF, Zhu B. The antibiotic resistome: gene flow in environments, animals and human beings. Front Med. 2017;11 (2):161-168. doi:10.1007/s11684-017-0531-x

41. Hu Y, Yang X, Li J, et al. The bacterial mobile resistome transfer network connecting the animal and human microbiomes. Appl Environ Microbiol. 2016;82(22):6672-6681. doi:10.1128/AEM.01802-16

42. Qiao M, Ying GG, Singer AC, Zhu YG. Review of antibiotic resistance in China and its environment. Environ Int. 2018;110:160-172. doi:10.1016/j.envint.2017.10.016

43. Hu FP, Guo Y, Zhu DM, et al. Resistance trends among clinical isolates in China reported from CHINET surveillance of bacterial resistance, 2005-2014. Clin Microbiol Infect. 2016;22(Suppl 1):S9S14. doi:10.1016/j.cmi.2016.01.001
Infection and Drug Resistance

\section{Publish your work in this journal}

Infection and Drug Resistance is an international, peer-reviewed openaccess journal that focuses on the optimal treatment of infection (bacterial, fungal and viral) and the development and institution of preventive strategies to minimize the development and spread of resistance. The journal is specifically concerned with the epidemiology of antibiotic resistance and the mechanisms of resistance development and diffusion in both hospitals and the community. The manuscript management system is completely online and includes a very quick and fair peerreview system, which is all easy to use. Visit http://www.dovepress.com/ testimonials.php to read real quotes from published authors. 